\title{
Effect of Essential Oil from Citronella and Alfazema on Fennel Aphids Hyadaphis foeniculi Passerini (Hemiptera: Aphididae) and its Predator Cycloneda sanguinea L. (Coleoptera: Coccinelidae)
}

\author{
${ }^{1}$ Charles I. Abramson, ${ }^{2}$ Paulo A. Wanderley, ${ }^{2}$ Maria J. A. Wanderley \\ ${ }^{3}$ Alexandre J. S. Miná and ${ }^{2}$ Orlando Baracho de Souza \\ ${ }^{1}$ Oklahoma State University, Laboratory of Comparative Psychology and Behavioral Biology \\ Departments of Psychology and Zoology, Stillwater, OK 74078, USA \\ ${ }^{2}$ Entomology Laboratory of the Universidade Federal da Paraiba Rua Antônio Alves da Rocha, \\ 12, Conj. Edgar St ${ }^{\mathrm{a}}$ Cruz, CEP 58220-000, Bananeiras, Paraiba, Brazil \\ ${ }^{3}$ Agronomy Laboratory of the Universidade Federal da Paraiba, Brazil
}

\begin{abstract}
The essential oil of plants is used as an alternative to pesticides for the control of aphids. We study the effect of the essential oils of citronella and alfazema on aphid populations in the laboratory and in the field. We also investigate the effect of these oils on the behavior of the aphid's principal predator the ladybug. The results show that alfazema is highly effective, more so than citronella. A $1 \%$ concentration of alfazema oil is more effective in killing aphids than the same concentration of citronella. Alfazema oil has the further advantage that it is attractive to ladybugs and is less lethal to fennel flowers.
\end{abstract}

Key words: Biological control, aphids, citronella, alfazema, ladybugs

\section{INTRODUCTION}

The aphid (Hyadaphis foeniculi Passerini) is the principal pest of fennel (Foeniculum vulgare Mill.) in the Agreste and Brejo regions in the Brazilian state of Paraiba. This insect sucks the juice of fennel plants often during the flower stage and can cause $100 \%$ loss to the flowers and fruit (P. A. Wanderley unpublished data). In Paraiba, aphids attack the fennel plants over a several month period (July - December). The aphid population during this period consists entirely of asexual producing females allowing the population to increase rapidly. Under ideal conditions aphids produce as many as 21 generations per year. When the population becomes to large, or food is scarce, aphids produce wings and migrate to new flowers ${ }^{[1]}$.

As the fennel in Paraiba is used to make tea and typical foods such as bread, the use of chemical insecticides to control this pest is dangerous to the small farmer, their families and consumers. Moreover the insecticide kills the natural enemies of aphids thereby increasing the population of these insects ${ }^{[2]}$.

One alternative method to control aphids is the use of essential oils and extracts. These products are described as complex mixtures of natural substances made by plants. They are used to repel or kill insect pests that feed on flowers, fruits, leaves and woods. One of these essential oils is citronella (Cymbopogon winterianus) which has been in use for 50 years ${ }^{[3]}$. We would like to suggest that alfazema Hyptis suaveolens (L.) Poit is also effective in controlling aphids.
Alfazema is an aromatic plant that grows in the northeast region of Brazil. The purpose of the experiments reported here is to demonstrate the effectiveness of alfazema oil on fennel aphids and comparing it to citronella. We also report an experiment on the effect of alfazema on the aphid predator Cycloneda sanguinea L. popularly known as the "Ladybug."

\section{MATERIALS AND METHODS}

Four experiments were conducted. The first two were laboratory investigations and the remainder conducted in the field. In the first experiment, aphids $H$. foeniculi were collected from fennel plants and brought to the Entomology Laboratory of the Universidade Federal da Paraiba.

One hundred adult aphids were placed in Petri dishes containing a fennel leaf. The aphids were treated with alfazema oil in four concentrations $(1 \%, 3 \%, 5 \%$ and $7 \%)$ and five doses $(0.2,0.4,0.6,1.0$ and $1.5 \mu \mathrm{L})$. A treatment was applied to the top of the abdomen and the insect released into a Petri dish. Each Petri dish contained 10 insects. To determine mortality, observations were made at $1,2,3$ and $4 \mathrm{hrs}$ post treatment. The same experiment was repeated with citronella oil with 100 newly collected adult aphids

In the second experiment we tested the effect of citronella and alfazema on $C$. sanguinea adults in open and closed environments. The rationale behind the use of two environments was to test the effect of citronella

Corresponding Author: $\quad$ Dr. C. I. Abramson, Laboratory of Comparative Psychology and Behavioral Biology, Departments of Psychology and Zoology, Oklahoma State University, 215 N. Murray, Stillwater, OK, Tel: (405) 744-7492, Fax: (405) 744-8067 
and alfazema in a closed space such as one that might be expected to contain an aphid. Fennel inflorescences were treated with citronella and alfazema oils in concentrations of $0 \%$ (water $+1 \%$ of neutral detergent), $1 \%$ and $5 \%$ and placed in an arena. The arena was constructed of plastic with a center circular compartment connected to 4 other compartments (Ward's Natural Science, Rochester, N.Y., Animal Behavior Investigation Tray, Product\# $14 \mathrm{~V}$ 8321). In these 4 compartments were placed one treated inflorescence. In the central compartment $10 \mathrm{C}$. sanguinea were released. After $10 \mathrm{~min}, 1,2$, and $3 \mathrm{hrs}$ post release, we counted the number of insects present on the fennel inflorescences. In the open system, the arena was covered with a plastic screen and in the closed system the arena was covered with an acrylic plate.

In the two field experiments we sprayed $4 \mathrm{~mL}$ of both citronella and alfazema in the same concentrations used in the laboratory experiments described earlier $(1 \%, 3 \%, 5 \%, 7 \%)$. The essential oils were sprayed directly on aphid colonies in fennel plants located in test fields. As a control, 50 aphids were treated with water + neutral detergent for each treatment. Immediately after treatment, fennel flowers were collected and the number of dead and live aphids counted at 1, 2, 3 and 4 hrs. We calculated the DL Do $_{50}$ and $\mathrm{TL}_{50}$ to both alfazema and citronella oils.

\section{RESULTS AND DISCUSSION}

The results of the laboratory experiment show that the citronella lethal doses were: 0.53 and $0.56 \mu \mathrm{L}$ to $1 \%$ and $3 \%$ concentrations, respectively. The 5\% and $7 \%$ concentrations of citronella oil were lethal to flowers. For alfazema oil, the lethal doses were: $0.56 ; 0.55 ; 0.24$ $\mu \mathrm{L}$ to $1 \%, 3 \%$ and $5 \%$, respectively. A $7 \%$ concentration of alfazema oil was lethal to flowers.

The results of the arena experiment in which we investigated the effect of open and closed systems, reveal that when the arena was covered with acrylic plate, the ladybugs died when sprayed with citronella, but did not when the arena was covered with a screen.

Ladybugs preference to flowers sprayed with citronella and alfazema oils are in Table 1. The number of ladybugs attracted to flowers sprayed with only detergent and water ( $0 \%$ concentration) in the arena with citronella oil was higher than to fennel flowers sprayed with detergent and water ( $0 \%$ concentration) with alfazema oil. Ladybugs are attracted to fennel flowers sprayed with $1 \%$ or $5 \%$ citronella oil but not as attracted when compared to the alfazema treatment. When fennel flowers were treated with $5 \%$ citronella or alfazema, ladybugs were not attracted as in the other treatments.

The results of the field experiments are in Table 2. The data shows that when aphids were sprayed with $1 \%$ citronella few insects died when compared to treatments of $3 \%, 5 \%$ and $7 \%$ citronella. When the aphids were sprayed with alfazema oil we observed high mortality at all concentrations tested.
Our results show that controlling the aphid $H$. foeniculi with the essential oil of alfazema is highly effective, more so than citronella. Of special interest is

Table 1: Ladybug preference to fennel flowers sprayed with citronella and alfazema oils $(n=10)$

\begin{tabular}{lll}
\hline $\begin{array}{l}\text { Concentration } \\
(\%)\end{array}$ & $\begin{array}{l}\text { Number of Insects } \\
\text { attracted to } \\
\text { Citronella } \pm \mathrm{SD}^{2}\end{array}$ & $\begin{array}{l}{ }^{1} \text { Number of Insects } \\
\text { attracted to Alfazema } \\
\pm \mathrm{SD}\end{array}$ \\
\hline 0 & $4.80 \pm 0.84$ & $2.20 \pm 0.84^{*}$ \\
1 & $1.20 \pm 0.45$ & $2.60 \pm 1.14^{* *}$ \\
5 & $2.80 \pm 0.45$ & $2.60 \pm 0.89$ \\
\hline 1. & $\begin{array}{l}\text { ANOVA between number of insects attracted to Citronella and } \\
\text { number of insects attracted to Alfazema; } 2 \text {. Standard Deviation; }\end{array}$ \\
$*$ & $\begin{array}{l}\text { Significant difference into the line }(\mathrm{P}<0,05) ; * * \text { Significant } \\
\text { difference into the line }(\mathrm{P}<0,01)\end{array}$
\end{tabular}

Table 2: Mortality of Hyadaphis foeniculi sprayed with citronella and alfazema oils

\begin{tabular}{lcll}
\hline Oils & $\begin{array}{l}\text { Concentrations } \\
(\%)\end{array}$ & $\begin{array}{l}\text { Number of } \\
\text { insects } \pm \text { SD }\end{array}$ & $\begin{array}{l}{ }^{1} \text { Died Insects } \\
(\%) \pm \text { SD }\end{array}$ \\
\hline \multirow{2}{*}{ Citronella } & 1 & $73.50 \pm 27.86$ & $81.15 \pm 5.36 \mathrm{a}$ \\
& 3 & $116.75 \pm 19.01$ & $98.10 \pm 0.77 \mathrm{~b}$ \\
& 5 & $132.50 \pm 19.23$ & $98.96 \pm 1.27 \mathrm{~b}$ \\
& 7 & $165.00 \pm 26.97$ & $93.80 \pm 2.78 \mathrm{~b}$ \\
& 1 & $265.25 \pm 69.68$ & $95.45 \pm 1.90 \mathrm{a}$ \\
Alfazema & 3 & $226.25 \pm 60.73$ & $95.19 \pm 1.87 \mathrm{a}$ \\
\multicolumn{4}{c}{} \\
\hline The data were transformed to $\sqrt{\mathrm{x}+0.5}$ & for ANOVA. The \\
\multicolumn{4}{c}{ significance level is 5\%. }
\end{tabular}

that a $1 \%$ concentration of alfazema oil is more effective in killing aphids than the same concentration of citronella. Alfazema oil has the further advantage that it is attractive to ladybugs ( $C$. sanguinea ) a natural predator of aphids and is less lethal to fennel flowers. Our future work will be directed toward large scale field tests and experiments on the effect of alfazema oil on reproductive and migratory behavior of $C$. sanguinea.

\section{ACKNOWLEDGEMENTS}

This work was supported by a grant from the Conselho Nacional de Pesquisa Cientifica e Tecnologica. The participation of Dr. Maria José Araújo Wanderley was provided by a grant from Desenvolvimento Cientifico Regional. Dr. Abramson's participation was supported in part from a visiting professor grant from the Universidade Estadual da Paraiba.

\section{REFERENCES}

1. Dimson, E.V. and K. Agnew, 2006. Crop Profile for Fennel in Arizona. Disponível em: http://cipm.ncsu.edu/cropprofiles/docs/azfennel.ht $\mathrm{ml}$.

2. Hassan, S.A., 1997. Métodos padronizados para testes de seletividade, com ênfase em Trichograma: 207-233. In: J.R.P. Parra and Zucchi (Eds.), Trichograma e o controle biológico aplicado. Piracicaba, Fealq.

3. Moschetti, R., 2006. Pesticides Made with Botanical oils and Extracts. Disponivel em: http://www.homestead.com/ipmofalaska/files/essen tialoils.html. 